\title{
Pragmatic Recommendations for the Use of Diagnostic Testing and Prognostic Models in Hospitalized Patients with Severe COVID-19 in Low- and Middle-Income Countries
}

\author{
Marcus J. Schultz, ${ }^{1,2,3,4 \star}$ Tewodros H. Gebremariam, ${ }^{5}$ Casey Park, ${ }^{6}$ Luigi Pisani,,${ }^{1,7,8}$ Chaisith Sivakorn, ${ }^{9}$ Shaurya Taran, ${ }^{6}$ and \\ Alfred Papali ${ }^{10}$ for the COVID-LMIC Task Force and the Mahidol-Oxford Research Unit (MORU) \\ ${ }^{1}$ Mahidol-Oxford Tropical Medicine Research Unit (MORU), Mahidol University, Bangkok, Thailand; ${ }^{2}$ Department of Intensive Care, Amsterdam \\ University Medical Centers, Location 'AMC', Amsterdam, The Netherlands; ${ }^{3}$ Laboratory of Experimental Intensive Care and Anesthesiology \\ (L.E.I.C.A), Amsterdam University Medical Centers, Location 'AMC', Amsterdam, The Netherlands; ${ }^{4}$ Nuffield Department of Medicine, Oxford \\ University, Oxford, United Kingdom; ${ }^{5}$ Department of Internal Medicine, College of Health Sciences, Tikur Anbessa Specialized Hospital, Addis \\ Ababa University, Addis Ababa, Ethiopia; 'Interdepartmental Division of Critical Care Medicine, Department of Medicine, Toronto, Canada; \\ ${ }^{7}$ Operational Research Unit, Doctors with Africa - CUAMM, Padova, Italy; ${ }^{8}$ Department of Anesthesia and Intensive Care, Miulli Regional Hospital, \\ Acquaviva delle Fonti, Italy; ${ }^{9}$ Department of Clinical Tropical Medicine, Mahidol University, Bangkok, Thailand; ${ }^{10}$ Division of Pulmonary and Critical \\ Care Medicine, Atrium Health, Charlotte, North Carolina
}

\begin{abstract}
Management of patients with severe or critical COVID-19 is mainly modeled after care of patients with severe pneumonia or acute respiratory distress syndrome from other causes. These models are based on evidence that primarily originates from investigations in high-income countries, but it may be impractical to apply these recommendations to resource-restricted settings in low- and middle-income countries (LMICs). We report on a set of pragmatic recommendations for microbiology and laboratory testing, imaging, and the use of diagnostic and prognostic models in patients with severe COVID-19 in LMICs. For diagnostic testing, where reverse transcription-PCR (RT-PCR) testing is available and affordable, we recommend using RT-PCR of the upper or lower respiratory specimens and suggest using lower respiratory samples for patients suspected of having COVID-19 but have negative RT-PCR results for upper respiratory tract samples. We recommend that a positive RT-PCR from any anatomical source be considered confirmatory for SARS-CoV-2 infection, but, because false-negative testing can occur, recommend that a negative RT-PCR does not definitively rule out active infection if the patient has high suspicion for COVID-19. We suggest against using serologic assays for the detection of active or past SARS-CoV-2 infection, until there is better evidence for its usefulness. Where available, we recommend the use of point-of-care antigen-detecting rapid diagnostic testing for SARS-CoV-2 infection as an alternative to RT-PCR, only if strict quality control measures are guaranteed. For laboratory testing, we recommend a baseline white blood cell differential platelet count and hemoglobin, creatinine, and liver function tests and suggest a baseline C-reactive protein, lactate dehydrogenase, troponin, prothrombin time (or other coagulation test), and $D$-dimer, where such testing capabilities are available. For imaging, where availability of standard thoracic imaging is limited, we suggest using lung ultrasound to identify patients with possible COVID-19, but recommend against its use to exclude COVID-19. We suggest using lung ultrasound in combination with clinical parameters to monitor progress of the disease and responses to therapy in COVID-19 patients. We currently suggest against using diagnostic and prognostic models as these models require extensive laboratory testing and imaging, which often are limited in LMICs.
\end{abstract}

\section{INTRODUCTION}

Management of patients with severe or critical COVID-19 is mainly based on care for patients with severe pneumonia or acute respiratory distress syndrome (ARDS) from other causes, although some aspects of this new disease may demand a different approach. Recommendations for treatment of severe pneumonia and ARDS management have been gathered mainly from investigations in resource-rich intensive care units (ICUs), mostly located in high-income countries (HICs). It may not be practical to apply these recommendations to resourcerestricted settings, particularly in low- and middle-income countries (LMICs). Indeed, high dependency units and ICUs in LMICs are frequently restricted in availability of infrastructure, equipment, medications, skilled nurses, and doctors. An international task force composed of members from LMICs and HICs, all with direct experience in various LMIC settings, critically appraised a list of questions regarding laboratory tests (including microbiology), lung imaging, and the use of diagnostic and prognostic models for patients with severe COVID-19. We provide a list of recommendations and

\footnotetext{
*Address correspondence to Marcus J. Schultz, Department of Intensive Care Amsterdam University Medical Centers, Location 'AMC', Meibergdreef 9, Amsterdam 1105 AZ, The Netherlands. E-mail: marcus.j.schultz@gmail.com
}

suggestions after pragmatic, experience-based appraisal. A summary of the recommendations is shown in Table 1. Note that although these recommendations are formulated specifically for hospitalized COVID-19 patients with severe or critical disease, as defined by the $\mathrm{WHO},{ }^{1}$ many are applicable to patients with lower severity of disease.

\section{METHODS}

A full description of the methods is provided in the appendix. In brief, we formulated a set of clearly defined questions regarding laboratory tests, imaging tools, and diagnostic and prognostic modeling for patients with suspected or confirmed severe/critical COVID-19 in LMICs. The list of questions was reviewed for content and clarity by other members of the COVID-LMIC Task Force. After approval, the subgroup assigned one member to search the literature for evidence to answer each question. The literature search was performed in a minimum of one general database (i.e., MEDLINE and Embase) and the Cochrane Library. We selected relevant publications, appraised the evidence, and classified the quality of evidence as high, moderate, low, or very low. Recommendations were rated as strong or weak, depending on the quality of evidence and several other factors such as availability, affordability, and feasibility in LMICs. A strong recommendation was worded as "we recommend..." and a 
TABLE 1

Recommendations and suggestions on microbiology and laboratory tests, imaging tools, and diagnostic and prognostic models in COVID-19 patients in LMICs (with grading)

\begin{tabular}{|c|c|c|}
\hline 1 & RT-PCR & $\begin{array}{l}\text { Where RT-PCR is available and affordable, we recommend using RT-PCR on upper or } \\
\text { lower respiratory specimens (strong recommendation, moderate quality of evidence) }\end{array}$ \\
\hline 2 & RT-PCR & $\begin{array}{l}\text { We suggest using lower respiratory samples in case a patient suspected of having } \\
\text { COVID-19 has a negative RT-PCR of the nasopharyngeal swab (weak } \\
\text { recommendation, low quality of evidence) }\end{array}$ \\
\hline 3 & RT-PCR & $\begin{array}{l}\text { We recommend that a positive RT-PCR from any anatomical source be considered } \\
\text { confirmatory for SARS-CoV-2 infection (strong recommendation, low quality of } \\
\text { evidence). Similarly, because false-negative testing can occur, we recommend that a } \\
\text { negative RT-PCR does not definitively rule out active infection if the patient has high } \\
\text { suspicion for COVID-19 (UG) }\end{array}$ \\
\hline 4 & $\mathrm{Ag}-\mathrm{RDT}$ & $\begin{array}{l}\text { In LMICs, where available, we recommend the use of point-of-care Ag-RDT for SARS- } \\
\text { CoV- } 2 \text { infection as an alternative to RT-PCR only if such testing is affordable, } \\
\text { performed by trained operators in accordance with test manufacturer } \\
\text { recommendations, and has } \geq 80 \% \text { sensitivity and } \geq 97 \% \text { specificity compared with } \\
\text { the local reference nucleic acid test (strong recommendation, low quality of evidence). } \\
\text { Where the minimal performance requirements are unknown, we suggest against use } \\
\text { of Ag-RDT point-of-care testing because of the high potential for false negatives (UG) }\end{array}$ \\
\hline 5 & Endemic infection & $\begin{array}{l}\text { We suggest that screening for endemic infectious illnesses occur at the time of COVID- } \\
19 \text { testing, as clinically appropriate (UG) }\end{array}$ \\
\hline 6 & Serologic assays & $\begin{array}{l}\text { We suggest against using serologic assays for the detection of active or past SARS- } \\
\text { CoV-2 infection, until there is better evidence for its usefulness (weak } \\
\text { recommendation, low quality of evidence) }\end{array}$ \\
\hline 7 & Hematology & $\begin{array}{l}\text { We recommend a baseline WBC, differential, platelet count and hemoglobin (strong } \\
\text { recommendation, moderate quality of evidence) }\end{array}$ \\
\hline 8 & Chemistry & $\begin{array}{l}\text { We recommend a baseline creatinine and liver function tests (strong recommendation, } \\
\text { moderate quality of evidence) }\end{array}$ \\
\hline 9 & $\begin{array}{l}\text { Cardiac enzymes and } \\
\text { acute phase proteins }\end{array}$ & $\begin{array}{l}\text { We suggest a baseline CRP, LDH, and troponin, where such testing capabilities are } \\
\text { available (weak recommendation, moderate quality of evidence) }\end{array}$ \\
\hline 10 & Coagulation & $\begin{array}{l}\text { We suggest a baseline prothrombin times, or other coagulation test, and } D \text {-dimer where } \\
\text { such testing capabilities are available (weak recommendation, moderate quality of } \\
\text { evidence) }\end{array}$ \\
\hline 11 & Ultrasound & $\begin{array}{l}\text { We suggest using LUS to identify patients with possible COVID-19 (weak } \\
\text { recommendation, low quality of evidence) }\end{array}$ \\
\hline 12 & Ultrasound & We recommend against using LUS to exclude COVID-19 (UG) \\
\hline 13 & Ultrasound & $\begin{array}{l}\text { We suggest using LUS in combination with clinical parameters to monitor progress of } \\
\text { disease and response to therapy in COVID-19 patients (weak recommendation, low } \\
\text { quality of evidence) }\end{array}$ \\
\hline 14 & Diagnostic and prognostic models & $\begin{array}{l}\text { We suggest against using diagnostic and prognostic models (weak recommendation, } \\
\text { low quality of evidence) }\end{array}$ \\
\hline
\end{tabular}

Ag-RDT = antigen-detecting rapid diagnostic testing; LMIC = low- and middle-income countries; LUS = lung ultrasound; RT-PCR = reverse transcription PCR; UG = ungraded. Grading: see Appendix for explanations.

weak recommendation as "we suggest...," followed by the quality of evidence. A number of recommendations could remain "ungraded" (UG), when, in the opinion of the subgroup members, such recommendations were not conducive for the process described previously (Table A2). The recommendations were reviewed by the subgroup in an iterative process and were later reviewed by the entire Task Force in two rounds.

\section{QUESTIONS}

We formulated four clearly defined questions regarding "microbiology and laboratory tests, imaging tools, and diagnostic and prognostic modeling":

1. In LMICs, which specific microbiology tests should be ordered for hospitalized patients to support a diagnosis of COVID-19?

2. In LMICs, which specific laboratory tests could be useful for hospitalized patients with severe COVID-19?

3. In LMICs, what is the role of lung ultrasound in patients with severe COVID-19?
4. In LMICs, are diagnostic and prognostic models useful in patients with severe COVID-19?

In LMICs, which specific microbiology tests should be ordered to support a diagnosis of COVID-19? Rationale. The diagnosis of COVID-19 infection can be made by using multiple methods, including detection of SARS-CoV-2 virus in upper respiratory tract samples, such as nasopharyngeal (NP) swabs, and lower respiratory tract samples, such as sputum and bronchial lavage samples. ${ }^{2}$ The sensitivity and specificity of tests vary according to the type of assays used, site sampled, and timing of specimen collection relative to the symptom onset. It is therefore crucial to recognize individual test characteristics before COVID-19 infection is reliably diagnosed.

In LMICs, COVID-19 diagnosis may be compounded by issues of cost, access, and feasibility of testing. However, there is little literature to guide a specific testing strategy, and the current Surviving Sepsis guidelines for COVID-19 do not recommend a tailored approach to LMICs. ${ }^{3}$ In this section, we summarize the existing literature on microbiologic testing with the goal of providing pragmatic and feasible recommendations from an LMIC perspective. 
Search results. MEDLINE, Embase, and Web of Science were searched through the end of October 2020. The search used combinations of medical subject headings (MeSH) terms and free-text words, including "COVID-19," "coronavirus," "SARSCoV-2," and "testing," "microbiology," "NP swab," "lavage," "endotracheal aspirate," "sputum," "serology," and "antibody." The search neither identified any publications from LMICs nor found articles with specific recommendations for LMICs.

Evidence. The most common strategy to diagnose COVID19 remains microbiologic testing of NP swabs. ${ }^{4}$ Samples are tested for SARS-CoV-2 by real-time PCR (RT-PCR), which, in the case of NP swabs, can yield detectable viral RNA even before symptom onset. Nasopharyngeal swabs, when properly collected, can have a sensitivity and specificity of $97 \%$ and $100 \%$, respectively, for SARS-CoV-2 detection, which is higher than those for oral specimens (56\% sensitivity and $99 \%$ specificity), nasal swabs (76\% sensitivity and $100 \%$ specificity), and saliva ( $85 \%$ sensitivity and $100 \%$ specificity). ${ }^{2}$ Diagnostic sensitivity can vary greatly from one institution to other institution and based on the testing kit. If suspicion for COVID-19 infection is high, but the initial NP RT-PCR is negative, and repeated sampling from multiple sites, including the lower airway, is advised to reduce the number of false negatives. Lower airway samples can be obtained via induced sputum, mid-trachea, or bronchoalveolar lavage. ${ }^{2}$ In a study of 15 patients, bronchoalveolar lavage fluid had a positivity rate of $93 \% .^{5}$ However, the decision to obtain lower airway samples must take into account the risk of aerosol generation and attendant contamination risk. Sputum induction and lower airway lavage are aerosol-generating procedures and may place hospital staff at risk. If appropriate personal protective equipment (PPE) shortage is a concern, these tests may not be safe or practical, and alternate sampling strategies should be considered (e.g., repeating NP swabs or obtaining tracheal aspirates, if the patient is intubated).

Point-of-care antigen-detecting rapid diagnostic testing (Ag-RDT) is increasingly available in LMIC settings. ${ }^{6}$ The quality and sensitivity of Ag-RDT varies widely depending on the specific test kit used. Available studies suggest that AgRDTs are most likely to detect SARS-CoV-2 virus at peak viral loads, such as in the presymptomatic or early symptomatic phases. False negatives are more likely if Ag-RDT testing occurs later in the illness, and false positives can occur if antibodies on the testing strip detect antigens from viruses that are not SARS-CoV-2. The WHO recommends that Ag-RDTs be performed within the first 5-7 days of symptom onset by trained operators who strictly follow the manufacturers' guidelines. Moreover, a minimal performance requirement of $\geq 80 \%$ sensitivity and $\geq 97 \%$ specificity compared with the local nucleic acid amplification test reference assay is necessary to ensure that more symptomatic cases are detected than missed. $^{7}$

Serologic testing of blood samples for anti-SARS-CoV-2 antibodies is also possible. Advantages include the requirement for less equipment and expertise to process, cheaper overall costs (e.g., rapid flow assays), and high specificity of validated assays when measured after 3 weeks of symptom onset. ${ }^{8-12}$ However, there are also important caveats. Rapid point-of-care versions of the test can be of variable quality, and the antigens tested are often not disclosed by manufacturers. ${ }^{4}$ Antibody testing also has low sensitivity within the first 2 weeks of infection. ${ }^{4}$ Current guidelines from HICs therefore recommend that serologic testing only be obtained after 3-4 weeks if laboratory or epidemiologic confirmation of infection is necessary, or in patients with repeatedly negative RT-PCR who are strongly suspected to have COVID-19. ${ }^{3}$

The possibility of coinfection with other viruses in patients with confirmed COVID-19 has been well described. ${ }^{13-15}$ In a single-region study from an $\mathrm{HIC}$, of 116 specimens positive for SARS-CoV-2, 24 (20.7\%) were also positive for one or more additional viral respiratory pathogens. ${ }^{13}$ The most common agents were rhinovirus/enterovirus $(6.9 \%)$, respiratory syncytial virus (5.2\%), and other Coronaviridae (4.3\%). However, in a systematic review of 30 studies assessing rates of coinfection (of which 23 were from China), the rate of viral coinfection was only $3 \%,{ }^{15}$ and the most common pathogens among coinfected individuals were respiratory syncytial virus (16.9\%) and influenza A (15.5\%).

Bacterial coinfections have also been commonly reported in patients with COVID-19. In two separate meta-analyses of 24 and 30 studies, bacterial coinfections were identified in $6.9 \%$ and $7.0 \%$ of patients, respectively. ${ }^{15,16}$ Bacterial coinfection in the first meta-analysis was identified in $3.5 \%$ of patients on presentation and $14.3 \%$ in hospital, ${ }^{16}$ and overall coinfection rates were higher in critically ill patients $(8.1 \%)$ than other hospitalized patients (5.9\%). In both meta-analyses, the three most common bacterial co-pathogens were $M y$ coplasma species, Haemophilus influenzae, and Pseudomonas aeruginosa. ${ }^{15,16}$ Most of the studies reported bacterial coinfection in the lungs.

Blood stream infection is also an important consideration in patients with confirmed COVID-19; whereas data are derived primarily from studies in HICs, no data are available from LMICs. In a multicenter study from New York City involving 28,011 patients, blood cultures were positive in only $3.8 \%$ of cases, and the majority of positive cultures (98\%) were detected within 4 days of incubation. ${ }^{17}$ By contrast, a singlecenter study of 78 critically ill patients from Italy demonstrated 45 episodes of ICU-acquired blood stream infection in 31 distinct patients. ${ }^{18}$ Taken together, the importance of testing for blood stream coinfection in COVID-19 patients in resource-restricted settings of many LMICs remains unclear. Last, because numerous endemic infections can present with influenza-like illness and high fever, the WHO recommends that communities with high rates of other endemic infections that cause fever (e.g., malaria, dengue, and tuberculosis) also screen for these infections on presentation per routine protocols. ${ }^{19}$

Availability, feasibility, affordability, and safety. In LMICs, laboratory confirmation of SARS-CoV-2 infection may be limited and heavily influenced by the availability and cost of the associated laboratory and human infrastructure including swabs, reagents, the equipment involved, and trained technicians for repairs and daily maintenance. Moreover, the introduction of new testing strategies around the world makes it challenging to pin down the average cost of testing in each country. In general, the absolute cost of testing for patients appears to be less in LMICs than $\mathrm{HICs},{ }^{20}$ but this reduced testing cost must be weighed against the local average income. Where there is the existing infrastructure to test for SARS-CoV-2, whether at the local, regional, or national level, RT-PCR or Ag-RDT may be preferred to confirm infection. However, if testing infrastructure is not in place, the cost of 
buying, maintaining (including the cost of reagents), and staffing testing capacity must be balanced with clinical services, need for PPE, and other preventative measures. Moreover, formal cost-utility analyses in LMIC settings are needed.

Recommendations and suggestions (Table 1). Pragmatic recommendations for repeat RT-PCR testing for de-isolation and hospital discharge are addressed in a separate article in this series (reference).

1. In LMICs where RT-PCR is available and affordable, we recommend using RT-PCR of the upper (NP) or lower (induced sputum, mid-trachea, or bronchoalveolar lavage) respiratory tract (strong recommendation, moderate quality of evidence).

2. In LMICs, we suggest using lower respiratory samples in case a patient suspected of having COVID-19 has a negative RT-PCR of the NP swab. However, sampling methods should consider the risk of aerosol generation and attendant contamination risks to healthcare workers (weak recommendation, low quality of evidence).

3. In LMICs, we recommend that a positive RT-PCR from any anatomical source be considered confirmatory for SARSCoV-2 infection (strong recommendation, low quality of evidence). Similarly, because false-negative testing can occur, we recommend that a negative RT-PCR does not definitively rule out active infection if the patient has high suspicion for COVID-19 (UG best practice statement).

4. In LMICs, where available, we recommend the use of pointof-care Ag-RDT for SARS-CoV-2 infection as an alternative to RT-PCR only if such testing is affordable, performed by trained operators in accordance with test manufacturer recommendations, and has $\geq 80 \%$ sensitivity and $\geq 97 \%$ specificity compared with the local reference nucleic acid test (strong recommendation, low quality of evidence). Where the minimal performance requirements are unknown, we suggest against the use of Ag-RDT pointof-care testing because of the high potential for false negatives (UG, best practice statement).

5. In LMICs, we suggest against using serologic assays for the detection of active or past SARS-CoV-2 infection until the clinical utility of such testing becomes clearer (weak recommendation, low quality of evidence).

6. In LMICs, we suggest that screening for endemic infectious illnesses occur at the time of COVID-19 testing, as clinically appropriate (UG best practice statement)

In LMICs, which specific laboratory tests could be useful in hospitalized COVID-19 patients? Rationale. A variety of laboratory investigations may aid in the diagnosis and management of COVID-19. Some markers may predict disease severity and progression to ARDS, thromboembolic complications, or multi-organ failure. The U.S. NIH COVID-19 treatment guidelines suggest performing the following laboratory tests as part of the initial evaluation of patients with severe and critical COVID-19 disease: a complete blood count with differential, metabolic profile, and liver and renal function tests. It also advises measuring the levels of inflammatory markers, such as C-reactive protein (CRP), $D$-dimer, and ferritin for their prognostic values, though not part of the standard care. $^{21}$ The WHO interim guidelines on the management of COVID-19 disease (May 27, 2020, September 11, 2020) however do not provide guidance on specific laboratory testing in COVID-19 patients. ${ }^{6,22}$ This section attempts to address this discrepancy with a focus on resourceconstrained LMIC settings.

Search results. MEDLINE, Embase, and Web of Science were searched through the end of September 2020. The search used combinations of $\mathrm{MeSH}$ terms and free-text words, including "COVID-19," "coronavirus," "SARSCoV-2," and "laboratory findings" or "laboratory abnormalities." Few of the studies originated from LMICs. The search identified two useful systematic reviews and meta-analyses. The search ${ }^{23,24}$ did not identify any randomized clinical studies.

Evidence. Hematology. Lymphopenia, leukocytosis, neutrophilia, and low hemoglobin predict progression toward severe COVID-19. ${ }^{25,26}$ White blood cell (WBC) and neutrophil counts are higher, and lymphocyte counts and hemoglobin are lower in patients who die. ${ }^{27}$ The neutrophil-to-lymphocyte ratio was one of the independent predictive factors for critical illness at hospital admission. ${ }^{28}$ Eosinophil counts correlate positively with lymphocyte counts in severe and non-severe COVID-19. ${ }^{29,30}$ Blood cell counts may be a useful diagnostic aid in patients with a suggestive history and imaging for COVID-19 but who test negative by RT-PCR. ${ }^{30-32}$

Coagulation. A more comprehensive discussion of $D$-dimer and other coagulation-related laboratory studies can be found in a separate article in this series (reference). In brief, $D$-dimer levels can increase and the prothrombin times (PT) can be longer in COVID-19 patients ${ }^{26}$; both predict severity of COVID-19. ${ }^{33} D$-dimer levels are higher in patients who need critical care and in non-survivors. ${ }^{34-36}$ Other coagulation tests also predict mortality, ${ }^{27}$ as does the presence of thrombocytopenia. ${ }^{25,37}$ The most recent International Society on Thrombosis and Hemostasis interim guidance document, at the time of revision (October 2020), suggests to monitor coagulopathy in patients with severe COVID-19, by measuring $D$-dimer levels, PT, and platelet counts every $2-3$ days ${ }^{38}$ to guide decisions on anticoagulant therapies.

Chemistry. Higher levels of lactate dehydrogenase (LDH), aspartate aminotransferase (AST), alanine aminotransferase (ALT), total bilirubin, and creatinine have been found in COVID19 patients, and all may have prognostic value. ${ }^{25,26}$ Chemistry abnormalities that seem most prognostic are LDH and ALT. In a clinical score developed for predicting, at hospital admission, which patients with COVID-19 may develop critical illness, $\mathrm{LDH}$ and direct bilirubin were among the 10 independent predictors of critical illness. ${ }^{28}$ Glucose, AST, LDH, urea, and creatinine levels are higher, and albumin levels are lower in non-survivors. ${ }^{27}$

Heart enzymes. Cardiac troponins may predict progression to severe COVID-19. ${ }^{15}$ High-sensitivity cardiac troponin I was higher in non-survivors. ${ }^{27}$ Troponin and brain natriuretic peptide levels are higher in non-survivors. ${ }^{39}$ Acute cardiac injury, defined as an increase in troponin $>$ 99th percentile of the upper reference limit, was found more often in nonsurvivors than survivors $(60 \% \text { versus } 1 \%)^{36}$ and was seen more often in critically ill patients than those who did not need critical care (22\% versus $2 \%) .{ }^{40}$ It remains uncertain whether higher levels were caused by cardiotoxic treatments.

Acute-phase proteins. C-reactive protein may have prognostication value in COVID-19. ${ }^{25,26}$ C-reactive protein levels, with a median value of 47.6 (range $20.6-87.1$ ) $\mathrm{mg} / \mathrm{L}$, are 
associated with disease severity, ${ }^{18}$ although in multiple regression analyses, CRP is not an independent predictor of death. $^{27}$

Availability, feasibility, affordability, and safety. Shortage of skilled technical personnel can be a challenge in some settings, particularly in rural areas. Laboratories in LMICs are often sparsely distributed, and access may be limited by economic or geographical factors. Where they do exist, clinical laboratories are often under-resourced and facilities such as electrical supply and water may be unreliable. Lack of access to laboratory testing in LMICs may deprive people of lifesaving treatment. ${ }^{29}$

Total WBC tests are readily available in most LMICs. Although differential counts may be much less available, we assume they are usually affordable and feasible. Creatinine and liver function tests are also available and affordable in many LMICs and do not need sophisticated laboratory facilities. ${ }^{41} \mathrm{C}$-reactive protein, $\mathrm{LDH}$, troponin, PT, $D$-dimer, other simple coagulation tests, and cardiac enzymes may not be universally available, particularly in the public sector. ${ }^{41}$ In the evaluation of chest pain and symptomatic deep vein thrombosis, however, they could be very useful. ${ }^{42,43}$

Recommendations and suggestions (Table 1).

1. In LMICs, in patients with severe COVID-19, we recommend a baseline WBC count with differential, platelet count creatinine and liver function tests (strong recommendation, moderate quality of evidence).

2. In LMICs, we suggest a baseline CRP, LDH, troponin, PT (or other coagulation test), and $D$-dimer, where such testing capabilities are available (weak recommendation, moderate quality of evidence).

In LMICs, what is the role of lung ultrasound in patients with severe COVID-19?. Rationale. Chest imaging can be essential in the diagnosis and management of patients with COVID-19. Published reports to date have focused mainly on standard chest x-ray (CXR) and chest computed tomography (CT). Abnormalities are very often present on CXR images of COVID-19 patients ${ }^{44}$; consolidations and ground-glass opacities have been reported in $47 \%$ and $33 \%$, respectively. Not all patients with COVID-19 have abnormalities on chest CT images. ${ }^{45}$ Patchy ground-glass opacities, typically in a bilateral and peripheral locations, and consolidations have been most commonly described. ${ }^{46-48}$ In light of the high sensitivity of an abnormal scan, CT has even been suggested as a primary diagnostic tool for COVID-19. ${ }^{49,50}$

Challenges with access to CT and, at times, even simple CXR may preclude the usefulness of these imaging techniques in LMICs. Lung ultrasound (LUS) is increasingly recognized as a chest imaging tool with a strong potential to guide management of critically ill patients and may represent a useful tool in patients with COVID-19.

Search results. MEDLINE, Embase, and Web of Science were searched until May 2020. The search used combinations of MeSH terms and free-text words, including "COVID-19," "coronavirus," "SARS-CoV-2," "'radiography," "chest radiography," "CT," "chest CT," "CT," "chest CT," "ultrasound," "LUS," and "lung ultrasonography." Several studies were found but none reporting data from LMICs.

Evidence. For the diagnosis of pneumonia from causes other than COVID-19, LUS has been found to be superior to standard CXR, and it approaches chest CT in terms of diagnostic accuracy. ${ }^{51-53}$ Lung ultrasound had a better diagnostic yield than CXR in the early diagnosis of H1N1 2009 viral pneumonia. ${ }^{54}$ Experience with LUS in patients with COVID-19 is rapidly growing, with the consistent finding that nearly all COVID-19 patients have an abnormal LUS. ${ }^{55}$ Four major findings are frequently described in COVID-19 patients (Figure 1), although the sensitivity and specificity of the following findings remain uncertain. ${ }^{56}$

1. focal, multifocal, or confluent B-lines (in $97 \%$ of cases);

2. pleural thickening (in $50 \%$ of cases);

3. subpleural and pleural consolidations (in $40 \%$ of cases); and

4. rarely, pleural effusions (in $16 \%$ of cases). ${ }^{57-61}$

A patchy distribution of multiform clusters alternating with "spared areas" (regions of normal lung parenchyma) is often observed. $^{62}$ One LUS finding of particular usefulness in COVID-19 is the "light beam," a broad, lucent, band-shaped, vertical artifact that moves rapidly with sliding (see https:// link.springer.com/article/10.1007/s00134-020-06048-9), which may correspond to early ground-glass alterations on a chest CT scan. The precise diagnostic accuracy of this sign is currently being tested in a prospective study. ${ }^{63}$

Early reports suggest that the extent of LUS findings correlate with severity of lung injury in COVID-19. ${ }^{45}$ In one review of LUS in patients with COVID-19, the relative number and distribution of B-lines and consolidations approximated other parameters of clinical severity, including oxygen saturation, need for supplemental oxygenation, and respiratory rate. ${ }^{64}$ The WHO clinical management guidelines suggest that LUS be used to assist in COVID-19 diagnosis and identify or exclude pulmonary complications. ${ }^{1}$

Potentially useful scoring systems for patients with COVID19 are summarized in Table 2 . A scoring system to quantify the degree of lung injury in patients with COVID-19 has been proposed for both ventilated and non-ventilated patients (Figure 1). ${ }^{65}$ In invasively ventilated patients, early quantification of the severity of lung involvement by LUS in patients with COVID-19 can be estimated by using the "LUS score,"66 which has been extensively tested in ARDS patients. ${ }^{67,68}$ The dynamic changes in aeration can then potentially be quantified by reassessing the LUS score (Figure 2). A previous study in Rwanda proposed the use of LUS combined with pulse oximetry to diagnose ARDS (from causes other than COVID19) in a cohort of primarily non-ventilated patients. ${ }^{69}$ This approach was externally validated in invasively ventilated patients in the Netherlands, ${ }^{70}$ but its performance in COVID19 ARDS remains to be established.

To our knowledge, there are currently no published studies comparing LUS with RT-PCR for the diagnosis of COVID-19. However, multiple studies looking at diagnosis (NCT0435180, NCT04370275, NCT04393402, NCT04338568, NCT04322487, and NCT04377035) or prognosis (NCT04379544, NCT04384055, and NCT04370249) are currently underway as of November 5, 2020. One of these studies is being performed in Turkey (NCT04399681).

Availability, feasibility, affordability, and safety. Data on the availability of ultrasound devices in LMICs remain limited. In a recent multicenter observational study in 54 Asian ICUs, 54\% of centers reported having a dedicated chest radiography apparatus versus $79 \%$ an ultrasound apparatus, ${ }^{71}$ and a 


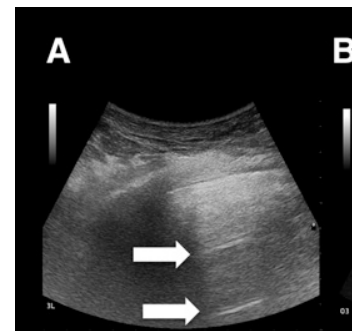

Normal lung with A-lines

E

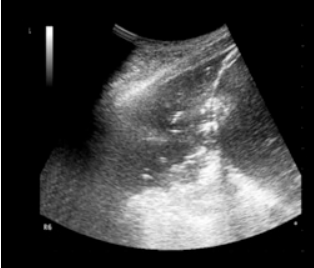

Lobar consolidation

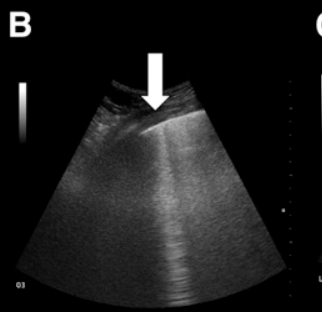

Focal B-line / 'light beam'

$\mathbf{F}$

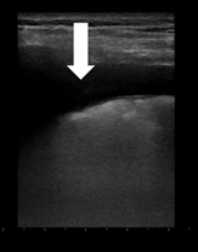

Pleural effusion

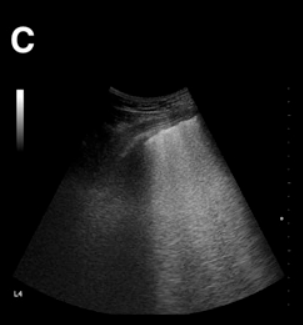

Confluent B-lines

G

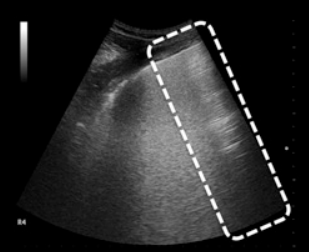

Spared area

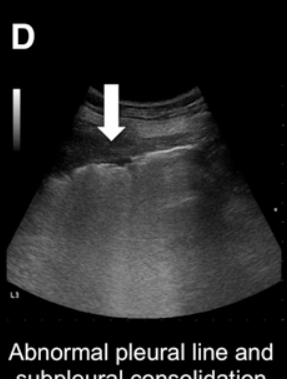

subpleural consolidation 
The ventilated patient is approached with adequate safety measures

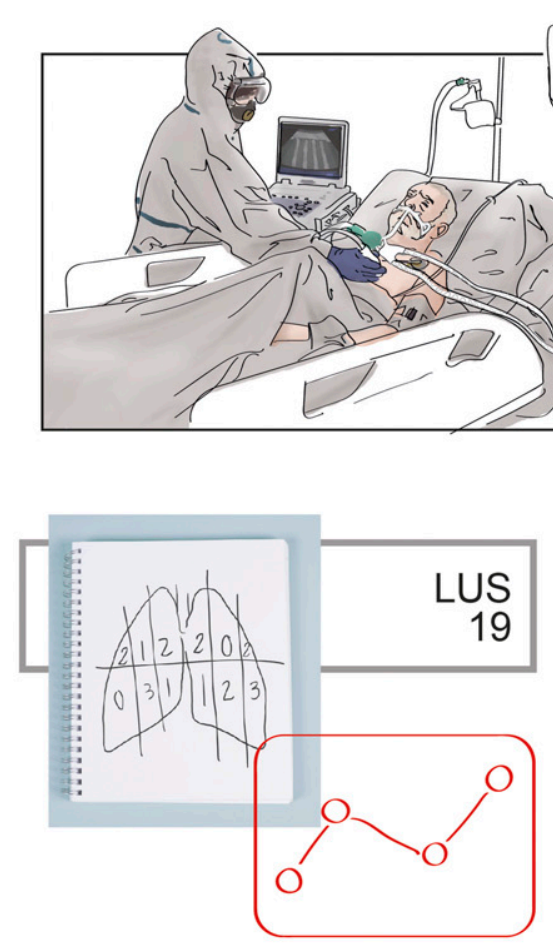

A comprehensive scan is performed using 4 or 6 lung regions per side

The global LUS score is computed and the trend followed in time

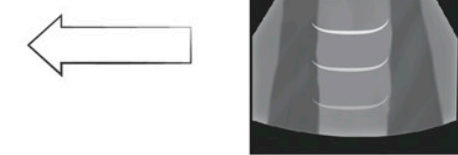

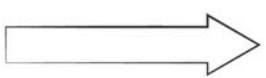

Score 0

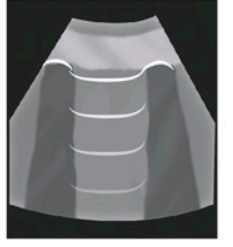

Score 0

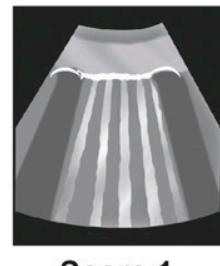

Score 1

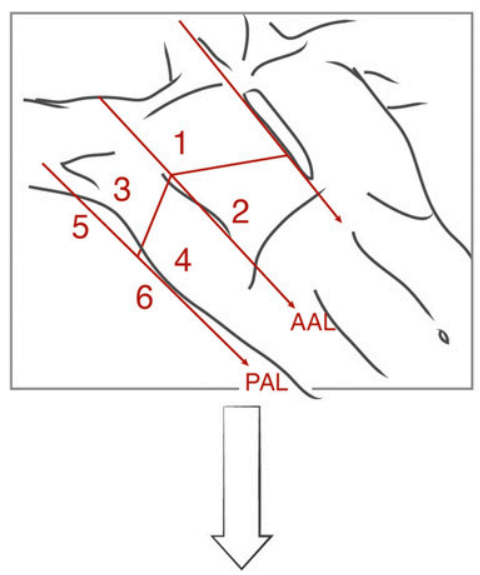

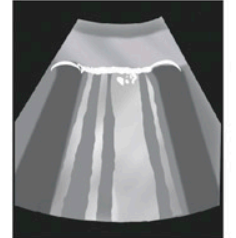

Score 2

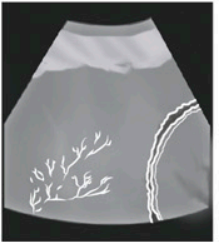

Score 3

A LUS aeration score is assigned to each lung region

FIGURE 2. Example on a potential use of LUS aeration scoring to monitor COVID-19 disease progression. (See also Table 2 for score details - several LUS scores can be used and followed in time.) AAL = anterior axillary line; LUS = lung ultrasound; PAL = posterior axillary line. Source: Produced by Luigi Pisani with thanks to Marco Rossetti for the graphical input; permission is granted for the reuse of this figure.

training. In an international, multicenter study across 10 ICUs, performance of 25 supervised LUS examinations resulted in sufficient acquisition of skills by non-experts for the assessment of the "LUS score." ${ }^{78}$ In more resource-restricted settings, a study of 20 participants in Ghana demonstrated good retention of cardiorespiratory ultrasonography principles 9-
11 months after participants received a training program. ${ }^{79}$ Point-of-care ultrasound training intervention in a resourcerestricted setting in Rwanda resulted in high numbers of diagnostic quality studies over long-term follow-up, ${ }^{80,81}$ although remote quality assurance feedback was found an effective educational tool in Uganda. ${ }^{82}$

TABLE 3

Diagnostic models

\begin{tabular}{|c|c|c|c|c|c|}
\hline Author (ref) & $\begin{array}{c}\text { Patients } \\
\text { (COVID-19 } \\
\text { patients) }\end{array}$ & Cohort description & Predictors & Application & Predictive performance \\
\hline $\begin{array}{l}\text { Meng } \\
\text { et al. }^{86}\end{array}$ & $620(302)$ & $\begin{array}{l}\text { China, asymptomatic } \\
\text { patients with } \\
\text { suspected or } \\
\text { confirmed COVID-19 }\end{array}$ & $\begin{array}{l}\text { Age, activated partial thromboplastin } \\
\text { time, red blood cell distribution width } \\
\text { SD, uric acid, triglyceride, serum } \\
\text { potassium, albumin/globulin, beta- } \\
\text { hydroxybutyrate, and serum calcium }\end{array}$ & $\begin{array}{l}\text { Downloadable from } \\
\text { Android and Apple } \\
\text { app store }\end{array}$ & $\begin{array}{l}\text { AUC of the testing and } \\
\text { validation set were } 0.841 \\
\text { and } 0.938 \text {, respectively; } \\
\text { PPV and NPV were } 86 \% \\
\text { and } 85 \% \text {, respectively }\end{array}$ \\
\hline $\begin{array}{l}\text { Feng } \\
\text { et al. }^{87}\end{array}$ & $132(26)$ & $\begin{array}{l}\text { China, feverish patients } \\
\text { with suspected } \\
\text { COVID-19 }\end{array}$ & $\begin{array}{l}\text { Age, temperature, heart rate, diastolic } \\
\text { blood pressure, systolic blood } \\
\text { pressure, basophil count, platelet } \\
\text { count, mean corpuscular hemoglobin } \\
\text { content, eosinophil count, monocyte } \\
\text { count, fever, shiver, shortness of } \\
\text { breath, headache, fatigue, sore throat, } \\
\text { fever classification, and interleukin } 6\end{array}$ & $\begin{array}{l}\text { https://intensivecare. } \\
\text { shinyapps.io/ } \\
\text { COVID19/ }\end{array}$ & $\begin{array}{l}\text { AUC of the testing and } \\
\text { validation set were } 0.890 \\
\text { and } 0.872 \text {, respectively }\end{array}$ \\
\hline $\begin{array}{l}\text { Song } \\
\text { et al. }^{88}\end{array}$ & 304 (73) & $\begin{array}{l}\text { China, hospitalized } \\
\text { patients with } \\
\text { suspected or } \\
\text { confirmed COVID-19 }\end{array}$ & $\begin{array}{l}\text { Fever, history of close contact, signs of } \\
\text { pneumonia on CT, neutrophil-to- } \\
\text { lymphocyte ratio, highest body } \\
\text { temperature, and gender }\end{array}$ & $\begin{array}{l}\text { Available as a score } \\
\text { chart (see } \\
\text { reference } 88 \text { ) }\end{array}$ & $\begin{array}{l}\text { Sensitivity and specificity } \\
\text { were } 93 \% \text { and } 87 \% \text {, } \\
\text { respectively }\end{array}$ \\
\hline
\end{tabular}




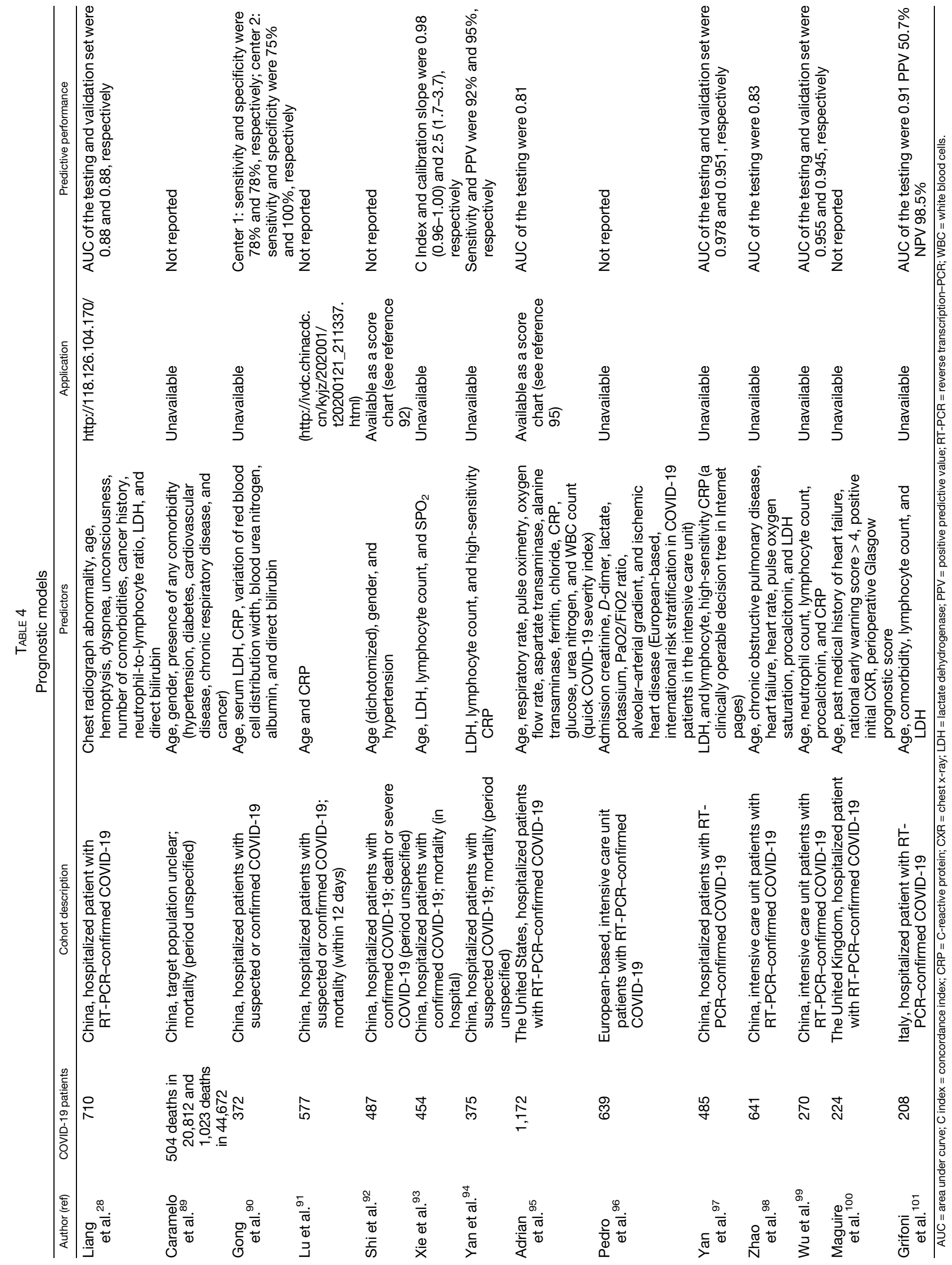


An important limitation of LUS is that it cannot detect lesions that are intrapulmonary and do not reach the pleural line. ${ }^{82}$ Usefulness of LUS via telemedicine is proposed, but direct evidence is still lacking. ${ }^{83}$

Recommendations and suggestions (Table 1).

1. In LMICs, where availability of standard CXR and CT is limited, we suggest using LUS to detect abnormalities to identify patients with possible COVID-19 (weak recommendation, low quality of evidence);

2. In LMICs, we recommend against the use of LUS to exclude COVID-19 (UG best practice statement);

3. In LMICs, we suggest using LUS in combination with clinical parameters to monitor progress of the disease and responses to therapy in COVID-19 patients (weak recommendation, low quality of evidence).

In LMICs, are diagnostic and prognostic models useful in patients with severe COVID-19?. Rationale. Healthcare systems have been under extreme pressure during the COVID-19 pandemic, and this includes those in LMICs. A definite diagnosis of COVID-19 requires detection of SARSCoV-2 by RT-PCR; however, these tests may have limited availability in LMICs, so a liberal testing strategy could be impractical in many settings.

Models conducted for accurately identifying an existing, but unknown, COVID-19 state (diagnostic) or prediction of COVID-19 severity and outcome (prognostic) purposes could assist in triaging patients when healthcare resources are restricted. ${ }^{84}$ Several models, ranging from rule-based scoring systems to "machine learning" or "deep learning" models have been proposed and published in the context of the COVID-19 pandemic.

Search results. MEDLINE, Embase, bioRxiv, medRxiv, and arXiv were searched through May 31, 2020. The search used combinations of $\mathrm{MeSH}$ terms and free-text words, including "COVID-19," "coronavirus," "novel corona," "SARS-CoV-2," "diagnostic," "diagnostic model," "prognostic," and "prognostic model." The initial search identified one systematic review, ${ }^{85}$ three COVID-19 diagnostic models in adult patients with suspected infection, ${ }^{86-88}$ and seven prognostic models for predicting mortality risk, progression to severe disease, or length of hospital stay. ${ }^{28,89-94}$ All models were built on data coming from Chinese patient cohorts. During the review process, an updated literature search through the end of October 2020 was conducted. Seven new prognostic models were found that directly answered the question, ${ }^{95-101}$ and two prognostic models ${ }^{92,95}$ are available as a score chart. All of these prognostic scores were based in HICs and used some laboratory testing often unaffordable or unavailable in LMIC settings, such as highsensitivity CRP, lactate, $D$-dimer, and procalcitonin.

Evidence. Tables 3 and 4 summarize several proposed diagnostic and prognostic models. ${ }^{28,86-101}$ All are based on distinct cohorts of patients infected with the SARS-CoV-2 virus, and most have been validated externally. Many of the models are available in commercial "app" stores, on dedicated Internet pages, or as a score chart.

Among the diagnostic models, Meng et al. ${ }^{86}$ used age and basic laboratories, whereas Feng et al. ${ }^{87}$ and Song et al. ${ }^{88}$ developed score charts using a combination of history and physical examination profiles, and more sophisticated diagnostic tests, such as interleukin- 6 or chest CT. Among the prognostic models, ${ }^{28,89-101}$ the authors developed models predicting development of severe illness or mortality among hospitalized COVID-19 patients using general history and physical examination profiles (e.g., age, gender comorbidities, and oxygen saturation, together with laboratory findings). Gong et al., ${ }^{90}$ Lu et al.,, ${ }^{91}$ Yan et al., ${ }^{94}$ Adrian et al., ${ }^{95}$ Yan et al., ${ }^{97}$ and Wu et al. ${ }^{99}$ used CRP in their prognostic models which might limit utility in LMICs.

The major caveats of these diagnostic and predictive models are that the discriminative performance of these models could differ in other patient cohorts and other geographic regions. In addition, all models were at high risk of bias, and therefore, performance of the models is likely to be too optimistic. Furthermore, sample sizes were rather small in many studies, increasing the risk of model overfitting. Future studies should address these concerns.

Availability, feasibility, affordability, and safety. Because laboratory testing and imaging availability often are constrained in LMICs, feasibility of the diagnostic and prognostic models for routine use may be poor. The models could become useful for decisions on when to use costly or limited available tests, such as RT-PCR. Such an approach could result in more efficient use of these tests and also increase the pretest likelihood of a positive result. It should be noted, though, that the models discovered in this literature review were not developed for this purpose.

Recommendations and suggestions (Table 1).

1. In LMICs, we currently suggest against using diagnostic and prognostic models (weak recommendation, low quality of evidence).

Received June 24, 2020. Accepted for publication January 11, 2021. Published online January 22, 2021.

Note: The Appendix can be found at www.ajtmh.org.

Financial support: Open access fees for this article and all others in this issue were supported by the Wellcome Trust of Great Britain.

Authors' addresses: Marcus J. Schultz, Mahidol-Oxford Tropical Medicine Research Unit (MORU), Mahidol University, Bangkok, Thailand, Department of Intensive Care, Amsterdam University Medical Centers, Location 'AMC', Amsterdam, The Netherlands, Laboratory of Experimental Intensive Care and Anesthesiology (L.E.I.C.A), Amsterdam University Medical Centers, Location 'AMC', Amsterdam, The Netherlands, and Nuffield Department of Medicine, Oxford University, Oxford, United Kingdom, E-mail: marcus.j.schultz@ gmail.com. Tewodros H. Gebremariam, Department of Internal Medicine, College of Health Sciences, Tikur Anbessa Specialized Hospital, Addis Ababa University, Addis Ababa, Ethiopia, E-mail: drtewodroshaile@gmail.com. Casey Park and Shaurya Taran, Interdepartmental Division of Critical Care Medicine, Department of Medicine, Toronto, Canada, E-mails: casey.park@medportal.ca and shaurya.taran@mail.utoronto.ca. Luigi Pisani, Mahidol-Oxford Tropical Medicine Research Unit (MORU), Mahidol University, Bangkok, Thailand, Operational Research Unit, Doctors with Africa - CUAMM, Padova, Italy, and Department of Anesthesia and Intensive Care, Miulli Regional Hospital, Acquaviva delle Fonti, Italy, E-mail: luigipisani@ gmail.com. Chaisith Sivakorn, Department of Clinical Tropical Medicine, Mahidol University, Bangkok, Thailand, E-mail: chaisith.siv@ mahidol.edu. Alfred Papali, Division of Pulmonary and Critical Care Medicine, Atrium Health, Charlotte, NC, E-mail: alfred.papali@ atriumhealth.org.

This is an open-access article distributed under the terms of the Creative Commons Attribution (CC-BY) License, which permits unrestricted use, distribution, and reproduction in any medium, provided the original author and source are credited.

\section{GROUP MEMBERS OF THE "COVID-LMIC TASK FORCE"}

Heads: Alfred Papali (Atrium Health, Charlotte, NC, USA) and Marcus Schultz (Mahidol University, Bangkok, Thailand; University of Oxford, 
Oxford, United Kingdom; Amsterdam University Medical Centers, location "AMC", Amsterdam, The Netherlands).

Advisors: Neill K. J. Adhikari (Interdepartmental Division of Critical Care Medicine, University of Toronto, Toronto, Canada); Emilie J. Calvello Hynes (University of Colorado School of Medicine, Department of Emergency Medicine, Denver, USA); Martin Dünser (Kepler University Hospital and Johannes Kepler University Linz, Linz, Austria) and Mervyn Mer (University of the Witwatersrand, Johannesburg, South Africa).

Subgroup members, in alphabetical order: Andrew Achilleos (Sunnybrook Health Sciences Centre, Toronto, Canada); Hanan Y. Ahmed (Department of Internal Medicine, College of Health Sciences, Addis Ababa University, Addis Ababa, Ethiopia); Kevan M. Akrami (Universidade Federal da Bahia, Faculdade de Medicina, Salvador, Brazil and Division of Infectious Disease, Department of Medicine, University of California San Diego, San Diego, USA); Lia M. Barros (University of Washington, Seattle, USA); B. Jason Brotherton (AIC Kijabe Hospital, Kijabe, Kenya); Sopheakmoniroth Chea (CalmetteHospital, Phnom Penh, Cambodia); William Checkley (The Johns Hopkins University School of Medicine and The Johns Hopkins University Center for Global Health, Baltimore, USA); Elif A. Cizmeci (Interdepartmental Division of Critical Care Medicine, Sunnybrook Health Sciences Centre, University of Toronto, Toronto, Canada); Natalie Cobb (University of Washington, Seattle, USA); Finot Debebe (Department of Emergency Medicine and Critical Care, Addis Ababa University School of Medicine, Addis Ababa, Ethiopia); Juliana Ferreira (University of São Paulo, São Paulo, Brasil); Gabriela Galli (University of Pittsburgh School of Medicine, Pittsburgh, USA); Tewodros Haile (Department of Internal Medicine, College of Health Sciences, Addis Ababa University); Bhakti Hansoti (Department of Emergency Medicine, Johns Hopkins University School of Medicine, Baltimore, USA); Madiha Hashmi (Ziauddin University, Karachi, Pakistan); Rebecca Inglis (Lao-Oxford-Mahosot Hospital-Wellcome Trust Research Unit (LOMWRU), Mahosot Hospital, Vientiane, Lao People's Democratic Republic and Department of Intensive Care, Oxford University Hospital Trust, Oxford, United Kingdom); Burton W. Lee (Critical Care Department, NIH, Bethesda, USA; Division of Pulmonary, Allergy and Critical Care, University of Pittsburgh School of Medicine, Pittsburgh, USA); Faith Lelei (AIC Kijabe Hospital, Kijabe, Kenya); Ganbold Lundeg (Mongolian National University of Medical Sciences, Ulan Bator, Mongolia); David Misango (The Aga Khan University, Nairobi, Kenya); Ary Serpa Neto (Department of Critical Care Medicine, Hospital Israelita Albert Einstein, São Paulo, Brazil; Australian and New Zealand Intensive Care Research Centre (ANZIC-RC), Monash University, Melbourne, Australia; Department of Intensive Care, Amsterdam University Medical Centers, location 'AMC', University of Amsterdam, Amsterdam, The Netherlands); Alfred Papali (Atrium Health, Charlotte, NC, USA); Casey Park (Interdepartmental Division of Critical Care Medicine, Sunnybrook Health Sciences Centre, University of Toronto, Toronto, Canada); Rajyabardhan Pattnaik (Ispat General Hospital, Rourkela, India); Jennifer L. Pigoga (Division of Emergency Medicine, University of South Africa, Cape Town, South Africa); Luigi Pisani (Department of Anesthesia and Intensive Care, Miulli Regional Hospital, Acquaviva delle Fonti, Italy; Doctors withAfrica - CUAMM, Padova, Italy; Mahidol-Oxford Tropical Medicine Research Unit (MORU), Mahidol University, Bangkok, Thailand); Elisabeth D. Riviello (Division of Pulmonary, Critical Care, and Sleep Medicine, Beth Israel Deaconess Medical Center and Harvard Medical School, Boston, USA); Kristina E. Rudd (University of Pittsburgh School of Medicine, Pittsburgh, USA); Marcus Schultz (Mahidol University, Bangkok, Thailand; University of Oxford, Oxford, United Kingdom; Amsterdam University Medical Centers, location "AMC", Amsterdam, The Netherlands); Varun U. Shetty (University of Pittsburgh Medical Center, Pittsburgh, USA); Gentle S. Shrestha (Tribhuvan University Teaching Hospital, Kathmandu, Nepal); Chaisith Sivakorn (Mahidol University, Salaya, Thailand); Shaurya Taran (Interdepartmental Division of Critical Care Medicine, University of Toronto, Toronto, Canada); T. Eoin West (University of Washington, Seattle, USA).

Group members of the subgroup "Diagnostic Testing and Prognostic Modeling": Marcus Schultz (Mahidol University, Bangkok, Thailand; University of Oxford, Oxford, UK; Amsterdam University Medical Centers, location "AMC", Amsterdam, The Netherlands); Tewodros Gebremariam (Department of Internal Medicine, College of
Health Sciences, Addis Ababa University), Casey Park (Interdepartmental Division of Critical Care Medicine, Toronto, Canada), Luigi Pisani (Mahidol-Oxford Tropical Medicine Research Unit' (MORU), Bangkok, Thailand), Chaisith Sivakorn (Department of Clinical Tropical Medicine, Bangkok, Thailand), Shaurya Taran (Interdepartmental Division of Critical Care Medicine, Toronto, Canada), and Alfred Papali (Atrium Health, Charlotte, NC, USA).

\section{REFERENCES}

1. WHO, 2020. Clinical Management of COVID-19: Interim Guidance. Geneva, Switzerland: World Health Organization. Available at: https://www.who.int/publications//item/clinical-management-ofcovid-19. Accessed January 7, 2021, 1-58.

2. Hanson KE et al., 2020. Infectious Diseases Society of America Guidelines on the Diagnosis of COVID-19. Clin Infect Dis (Epub ahead of print, 2020 Jun 16): ciaa760. doi: 10.1093/cid/ciaa760.

3. Alhazzani W, Møller MH, Arabi YM, Loeb M, Gong MN, Fan E, Oczkowski S, Levy MM, Derde L, Dzierba A, 2020. Surviving sepsis campaign: guidelines on the management of critically ill adults with coronavirus disease 2019 (COVID-19). Intensive Care Med 48: e440-e469.

4. Sethuraman N, Jeremiah SS, Ryo A, 2020. Interpreting diagnostic tests for SARS-CoV-2. JAMA 323: 2249-2251.

5. Wang W, Xu Y, Gao R, Lu R, Han K, Wu G, Tan W, 2020. Detection of SARS-CoV-2 in different types of clinical specimens. JAMA 323: $1843-1844$.

6. WHO, 2020. Diagnostic Testing for SARS-CoV-2: Interim Guidance. Geneva, Switzerland: World Health Organization. Available at: https://www.euro.who.int/en/health-topics/health-emergencies/ coronavirus-covid-19/publications-and-technical-guidance/ 2020/diagnostic-testing-for-sars-cov-2-interim-guidance,-11september-2020. Accessed January 7, 2021.

7. WHO, 2020. Antigen-Detection in the Diagnosis of SARS-CoV-2 Infection Using Rapid Immunoassays: Interim Guidance. Geneva, Switzerland: World Health Organization. Available at: https://apps.who.int/iris/handle/10665/334253. Accessed January $7,2021$.

8. Lou B et al., 2020. Serology characteristics of SARS-CoV-2 infection since exposure and post symptom onset. Eur Respir $J$ 56: 2000763

9. Ma H, Zeng W, He H, Zhao D, Jiang D, Zhou P, Cheng L, Li Y, Ma $X$, Jin T, 2020. Serum IgA, IgM, and IgG responses in COVID-19. Cell Mol Immunol 17: 773-775.

10. Pickering S, Betancor G, Galao RP, Merrick B, Signell AW, Wilson HD, Ik MTK, Seow J, Graham C, Acors S, 2020. Comparative assessment of multiple COVID-19 serological technologies supports continued evaluation of point-of-care lateral flow assays in hospital and community healthcare settings. PLoS Pathog 16: e1008817.

11. Van Elslande J, Houben E, Depypere M, Brackenier A, Desmet S, André E, Van Ranst M, Lagrou K, Vermeersch P, 2020. Diagnostic performance of $7 \mathrm{rapid} / \mathrm{lg} / \mathrm{lgM}$ antibody tests and the Euroimmun IgA/lgG ELISA in COVID-19 patients. Clin Microbiol Infect 26: 1082-1087.

12. Xiang $F$, Wang $X$, He X, Peng Z, Yang B, Zhang J, Zhou Q, Ye H, $\mathrm{Ma} \mathrm{Y,} \mathrm{Li} \mathrm{H,} \mathrm{2020.} \mathrm{Antibody} \mathrm{detection} \mathrm{and} \mathrm{dynamic} \mathrm{character-}$ istics in patients with coronavirus disease 2019. Clin Infect Dis 71: 1930-1934.

13. Kim D, Quinn J, Pinsky B, Shah NH, Brown I, 2020. Rates of coinfection between SARS-CoV-2 and other respiratory pathogens. JAMA 323: 2085-2086.

14. WuX, Cai Y, Huang X, Yu X, Zhao L, Wang F, Li Q, Gu S, Xu T, Li Y, 2020. Co-infection with SARS-CoV-2 and influenza $A$ virus in patient with pneumonia, China. Emerg Infect Dis 26: 1324-1326.

15. Lansbury L, Lim B, Baskaran V, Lim WS, 2020. Co-infections in people with COVID-19: a systematic review and meta-analysis. $J$ Infect 81: 266-275.

16. Langford BJ, So M, Raybardhan S, Leung V, Westwood D, MacFadden DR, Soucy JPR, Daneman N, 2020. Bacterial coinfection and secondary infection in patients with COVID-19: a living rapid review and meta-analysis. Clin Microbiol Infect 26: 1622-1629. 
17. Sepulveda J, Westblade LF, Whittier S, Satlin MJ, Greendyke WG, Aaron JG, Zucker J, Dietz D, Sobieszczyk M, Choi JJ, 2020. Bacteremia and blood culture utilization during COVID19 surge in New York city. J Clin Microbiol 58: e00875-20.

18. Giacobbe DR, Battaglini D, Ball L, Brunetti I, Bruzzone B, Codda G, Crea F, De Maria A, Dentone C, Di Biagio A, 2020. Bloodstream infections in critically ill patients with COVID-19. Eur J Clin Invest 50: e13319.

19. WHO, 2020. WHO COVID-19 Case Definition. Geneva, Switzerland: World Health Organization. Available at: https://www. who.int/publications/i/item/WHO-2019-nCoV-Surveillance_ Case_Definition-2020.1. Accessed January 7, 2021.

20. Desk EW, 2020. How Much Do COVID-19 Tests Cost in India? Here's a State-wise Breakup. Available at: https:// indianexpress.com/article/india/covid-19-test-prices-ratesindia-6896237/. Accessed January 7, 2021.

21. National Institutes of Health, 2020. Clinical Presentation of People with SARS-CoV-2 Infection. Available at: https:// www.covid19treatmentguidelines.nih.gov/overview/clinicalpresentation/. Accessed January 7, 2021.

22. World Health Organization, 2020. Laboratory Testing Strategy Recommendations for COVID-19: Interim Guidance. Geneva, Switzerland: World Health Organization. Available at: https:// apps.who.int/iris/handle/10665/331509. Accessed January 7, 2021.

23. Elshazli RM, Toraih EA, Elgaml A, El-Mowafy M, El-Mesery M, Amin MN, Hussein MH, Killackey MT, Fawzy MS, Kandil E, 2020. Diagnostic and prognostic value of hematological and immunological markers in COVID-19 infection: a meta-analysis of 6320 patients. PloS One 15: e0238160.

24. Xie Y, Wang Z, Liao H, Marley G, Wu D, Tang W, 2020. Epidemiologic, clinical, and laboratory findings of the COVID-19 in the current pandemic: systematic review and meta-analysis. $B M C$ Infect Dis 20: 640.

25. Guan WJ, Ni ZY, Hu Y, Liang WH, Ou CQ, He JX, Liu L, Shan H, Lei CL, Hui DS, 2020. Clinical characteristics of coronavirus disease 2019 in China. N Engl J Med 382: 1708-1720.

26. Lippi G, Plebani M, 2020. Laboratory abnormalities in patients with COVID-2019 infection. Clin Chem Lab Med 58: $1131-1134$.

27. Bonetti G, Manelli F, Patroni A, Bettinardi A, Borrelli G, Fiordalisi G, Marino A, Menolfi A, Saggini S, Volpi R, 2020. Laboratory predictors of death from coronavirus disease 2019 (COVID-19) in the area of Valcamonica, Italy. Clin Chem Lab Med 58: 1100-1105.

28. Liang W et al., 2020. Development and validation of a clinical risk score to predict the occurrence of critical illness in hospitalized patients with COVID-19. JAMA Intern Med 180: 1081-1089.

29. Zhang JJ, Dong X, Cao YY, Yuan YD, Yang YB, Yan YQ, Akdis CA, Gao YD, 2020. Clinical characteristics of 140 patients infected with SARS-CoV-2 in Wuhan, China. Allergy 75: $1730-1741$.

30. Rodriguez C, 2020. The Global Helminth Belt and COVID-19: The New Eosinophilic Link. Available at: https://www.qeios.com/ read/IWKQH9.2. Accessed January 7, 2021.

31. Rodriguez-Morales AJ, Cardona-Ospina JA, Gutiérrez-Ocampo E, Villamizar-Peña R, Holguin-Rivera Y, Escalera-Antezana JP, Alvarado-Arnez LE, Bonilla-Aldana DK, Franco-Paredes C, Henao-Martinez AF, 2020. Clinical, laboratory and imaging features of COVID-19: a systematic review and meta-analysis. Trav Med Infect Dis 34: 1016232.

32. Richardson S, Hirsch JS, Narasimhan M, Crawford JM, McGinn T, Davidson KW, Barnaby DP, Becker LB, Chelico JD, Cohen SL, 2020. Presenting characteristics, comorbidities, and outcomes among 5700 patients hospitalized with COVID-19 in the New York city area. JAMA 323: 2052-2059.

33. Han H, Yang L, Liu R, Liu F, Wu KL, Li J, Liu XH, Zhu CL, 2020. Prominent changes in blood coagulation of patients with SARS-CoV-2 infection. Clin Chem Lab Med 58: 1116-1120.

34. Huang C, Wang Y, LiX, Ren L, Zhao J, HuY, Zhang L, Fan G, Xu J, Gu X, 2020. Clinical features of patients infected with 2019 novel coronavirus in Wuhan, China. Lancet 395: 497-506.

35. Tang N, Li D, Wang X, Sun Z, 2020. Abnormal coagulation parameters are associated with poor prognosis in patients with novel coronavirus pneumonia. J Thromb Haemost 18: 844-847.
36. Zhou F, Yu T, Du R, Fan G, Liu Y, Liu Z, Xiang J, Wang Y, Song B, GuX, 2020. Clinical course and risk factors for mortality of adult inpatients with COVID-19 in Wuhan, China: a retrospective cohort study. Lancet 395: 1054-1062.

37. Yang X, Yang Q, Wang Y, Wu Y, Xu J, Yu Y, Shang Y, 2020. Thrombocytopenia and its association with mortality in patients with COVID-19. J Thromb Haemost 18: 1469-1472.

38. Thachil J, Tang N, Gando S, Falanga A, Cattaneo M, Levi M, Clark C, Iba T, 2020. ISTH interim guidance on recognition and management of coagulopathy in COVID-19. J Thromb Haemost 18: 1023-1026.

39. Guo T, Fan Y, Chen M, Wu X, Zhang L, He T, Wang H, Wan J, Wang X, Lu Z, 2020. Cardiovascular implications of fatal outcomes of patients with coronavirus disease 2019 (COVID-19). JAMA Cardiol 5: 811-818.

40. Wang D, Hu B, Hu C, Zhu F, Liu X, Zhang J, Wang B, Xiang H, Cheng Z, Xiong Y, 2020. Clinical characteristics of 138 hospitalized patients with 2019 novel coronavirus-infected pneumonia in Wuhan, China. JAMA 323: 1061-1069.

41. Horton S, Fleming KA, Kuti M, Looi L-M, Pai SA, Sayed S, Wilson $M L, 2019$. The top 25 laboratory tests by volume and revenue in five different countries. Am J Clin Pathol 151: 446-451.

42. Anderson F, Fritz M, Kontos M, McPherson R, Jesse R, 1998. Cost-effectiveness of cardiac troponin I in a systematic chest pain evaluation protocol: use of cardiac troponin I lowers length of stay for low-risk cardiac patients. Clin Lab Manag Rev 12: 63-69.

43. Crippa L, D’Angelo SV, Tomassini L, Rizzi B, D'Alessandro G, D'Angelo A, 1997. The utility and cost-effectiveness of D-dimer measurements in the diagnosis of deep vein thrombosis. Haematologica 82: 446-451.

44. Wong HYF, Lam HYS, Fong AHT, Leung ST, Chin TWY, Lo CSY, Lui MMS, Lee JCY, Chiu KWH, Chung T, 2020. Frequency and distribution of chest radiographic findings in COVID-19 positive patients. Radiology 296: E72-E78.

45. Xu X, Yu C, Qu J, Zhang L, Jiang S, Huang D, Chen B, Zhang Z, Guan W, Ling Z, 2020. Imaging and clinical features of patients with 2019 novel coronavirus SARS-CoV-2. Eur J Nucl Med Mol Imaging 47: 1275-1280.

46. LiX, Zeng W, LiX, Chen H, Shi L, LiX, Xiang H, Cao Y, Chen H, Liu C, 2020. CT imaging changes of corona virus disease 2019 (COVID-19): a multi-center study in southwest China. J Trans/ Med 18: 154.

47. Liu KC, Xu P, Lv WF, Qiu XH, Yao JL, Jin-Feng G, 2020. CT manifestations of coronavirus disease-2019: a retrospective analysis of 73 cases by disease severity. Eur J Radiol 126: 108941.

48. Chung M, Bernheim A, Mei X, Zhang N, Huang M, Zeng X, Cui J, Xu W, Yang Y, Fayad ZA, 2020. CT imaging features of 2019 novel coronavirus (2019-nCoV). Radiology 295: 202-207.

49. Ai T, Yang Z, Hou H, Zhan C, Chen C, Lv W, Tao Q, Sun Z, Xia L, 2020. Correlation of chest CT and RT-PCR testing in coronavirus disease 2019 (COVID-19) in China: a report of 1014 cases. Radiology 296: E32-E40.

50. Long C, Xu H, Shen Q, Zhang X, Fan B, Wang C, Zeng B, Li Z, LiX, $\mathrm{Li} \mathrm{H}, 2020$. Diagnosis of the coronavirus disease (COVID-19): rRT-PCR or CT? Eur J Radiol 126: 108961.

51. Nazerian P, Volpicelli G, Vanni S, Gigli C, Betti L, Bartolucci M, Zanobetti M, Ermini FR, lannello C, Grifoni S, 2015. Accuracy of lung ultrasound for the diagnosis of consolidations when compared to chest computed tomography. Am J Emerg Med 33: 620-625.

52. Reissig A, Copetti R, Mathis G, Mempel C, Schuler A, ZechnerP, Aliberti S, Neumann R, Kroegel C, Hoyer H, 2012. Lung ultrasound in the diagnosis and follow-up of community-acquired pneumonia: a prospective, multicenter, diagnostic accuracy study. Chest 142: 965-972.

53. Ye X, Xiao H, Chen B, Zhang S, 2015. Accuracy of lung ultrasonography versus chest radiography for the diagnosis of adult community-acquired pneumonia: review of the literature and meta-analysis. PLoS One 10: e0130066.

54. Testa A, Soldati G, Copetti R, Giannuzzi R, Portale G, GentiloniSilveri N, 2012. Early recognition of the 2009 pandemic influenza A (H1N1) pneumonia by chest ultrasound. Crit Care 16: R30. 
55. Mohamed MF, Al-Shokri S, Yousaf Z, Danjuma M, Parambil J, Mohamed S, Mubasher M, Dauleh MM, Hasanain B, AlKahlout $M A, 2020$. Frequency of abnormalities detected by point-ofcare lung ultrasound in symptomatic COVID-19 patients: systematic review and meta-analysis. Am J Trop Med Hyg 103: 815-821.

56. Denault AY, Delisle S, Canty D, Royse A, Royse C, Serra XC, Gebhard CE, Couture ÉJ, Girard M, Cavayas YA, 2020. A proposed lung ultrasound and phenotypic algorithm for the care of COVID-19 patients with acute respiratory failure. Can $J$ Anaesth 21: 1-12.

57. Peng Q, Wang X, Zhang L; Chinese Critical Care Ultrasound Study Group (CCUSG), 2019. Findings of lung ultrasonography of novel corona virus pneumonia during the 2019-2020 epidemic. Intensive Care Med 46: 849-850.

58. Vetrugno L, Bove T, Orso D, Barbariol F, Bassi F, Boero E, Ferrari G, Kong R, 2020. Our Italian experience using lung ultrasound for identification, grading and serial follow-up of severity of lung involvement for management of patients with COVID-19. Echocardiography 37: 625-627.

59. Poggiali E, Dacrema A, Bastoni D, Tinelli V, Demichele E, Mateo Ramos P, Marcianò T, Silva M, Vercelli A, Magnacavallo A, 2020. Can lung US help critical care clinicians in the early diagnosis of novel coronavirus (COVID-19) pneumonia? Radiology 295: E6.

60. Lomoro P, Verde F, Zerboni F, Simonetti I, Borghi C, Fachinetti C, Natalizi A, Martegani A, 2020. COVID-19 pneumonia manifestations at the admission on chest ultrasound, radiographs, and $\mathrm{CT}$ : single-center study and comprehensive radiologic literature review. Eur J Radiol 7: 100231.

61. Yasukawa K, Minami T, 2020. Point-of-care lung ultrasound findings in patients with COVID-19 pneumonia. Am J Trop Med Hyg 102: 1198-1202.

62. Volpicelli G, Gargani L, 2020. Sonographic signs and patterns of COVID-19 pneumonia. Ultrasound J 12: 22.

63. Volpicelli G, Lamorte A, Villén T, 2020. What's new in lung ultrasound during the COVID-19 pandemic. Intensive Care Med 4: $1445-1448$.

64. Smith M, Hayward S, Innes S, Miller A, 2020. Point-of-care lung ultrasound in patients with COVID-19-a narrative review. Anaesthesia 75: 1096-1104.

65. Soldati G, Smargiassi A, Inchingolo R, Buonsenso D, Perrone T, Briganti DF, Perlini S, Torri E, Mariani A, Mossolani EE, 2020. Proposal for international standardization of the use of lung ultrasound for patients with COVID-19: a simple, quantitative, reproducible method. J Ultrasound Med 39: 1413-1419.

66. Bouhemad B, Brisson H, Le-Guen M, Arbelot C, Lu Q, Rouby J-J, 2011. Bedside ultrasound assessment of positive endexpiratory pressure-induced lung recruitment. Am J Respir Crit Care Med 183: 341-347.

67. Mongodi S, Bouhemad B, Orlando A, Stella A, Tavazzi G, Via G, lotti GA, Braschi A, Mojoli F, 2017. Modified lung ultrasound score for assessing and monitoring pulmonary aeration. Ultraschall Med 38: 530-537.

68. Pisani L, Vercesi V, van Tongeren PS, Lagrand WK, Leopold SJ, Huson MA, Henwood PC, Walden A, Smit MR, Riviello ED, 2019. The diagnostic accuracy for ARDS of global versus regional lung ultrasound scores-a post hoc analysis of an observational study in invasively ventilated ICU patients. Intensive Care Med Exp 7: 44

69. Riviello ED, Kiviri W, Twagirumugabe T, Mueller A, BannerGoodspeed VM, Officer L, Novack V, Mutumwinka M, Talmor DS, Fowler RA, 2016. Hospital incidence and outcomes of the acute respiratory distress syndrome using the Kigali modification of the Berlin definition. Am J Respir Crit Care Med 193: 52-59.

70. Vercesi V, Pisani L, van Tongeren PS, Lagrand WK, Leopold SJ, Huson MM, Henwood PC, Walden A, Smit M, Riviello ED, 2018. External confirmation and exploration of the Kigali modification for diagnosing moderate or severe ARDS. Intensive Care Med 44: 523-524.

71. Pisani L et al., 2020. Epidemiological characteristics, ventilator management and clinical outcome in patients receiving invasive ventilation in intensive care units from 10 Asian middle-income countries (PRoVENT-iMiC) - an international, multicentre, prospective study. Am J Trop Med Hyg (Epub ahead of print, 2021 Jan 11). doi: 10.4269/ajtmh.20-1177.

72. Losonczy LI, Barnes SL, Liu S, Williams SR, McCurdy MT, Lemos V, Chandler J, Colas LN, Augustin ME, Papali A, 2019. Critical care capacity in Haiti: a nationwide cross-sectional survey. PLoS One 14: e0218141.

73. Groen RS, Leow JJ, Sadasivam V, Kushner AL, 2011. Indications for ultrasound use in low-and middle-income countries. Trop Med Int Health. 16: 1525-1535.

74. Becker DM, Tafoya CA, Becker SL, Kruger GH, Tafoya MJ, Becker TK, 2016. The use of portable ultrasound devices in lowand middle-income countries: a systematic review of the literature. Trop Med Int Health 21: 294-311.

75. Stewart KA, Navarro SM, Kambala S, Tan G, Poondla R, Lederman S, Barbour K, Lavy C, 2020. Trends in ultrasound use in low and middle income countries: a systematic review. Int $J$ MCH AIDS 9: 103-120.

76. Brogi E, Bignami E, Sidoti A, Shawar M, Gargani L, Vetrugno L, Volpicelli G, Forfori F, 2017. Could the use of bedside lung ultrasound reduce the number of chest $X$-rays in the intensive care unit? Cardiovasc Ultrasound 15: 23.

77. Oks M, Cleven KL, Cardenas-Garcia J, Schaub JA, Koenig S, Cohen RI, Mayo PH, Narasimhan M, 2014. The effect of pointof-care ultrasonography on imaging studies in the medical ICU: a comparative study. Chest 146: 1574-1577.

78. Rouby J-J, Arbelot C, Gao Y, Zhang M, Lv J, An Y, Chunyao W, Bin D, Valente Barbas CS, Dexheimer Neto FL, 2018. Training for lung ultrasound score measurement in critically ill patients. Am J Respir Crit Care Med 198: 398-401.

79. Osei-Ampofo M, Tafoya MJ, Tafoya CA, Oteng RA, Ali H, Becker TK, 2018. Skill and knowledge retention after training in cardiopulmonary ultrasound in Ghana: an impact assessment of bedside ultrasound training in a resource-limited setting. Emerg Med J 35: 704-707.

80. Henwood PC, Mackenzie DC, Rempell JS, Douglass E, Dukundane D, Liteplo AS, Leo MM, Murray AF, Vaillancourt S, Dean AJ, 2016. Intensive point-of-care ultrasound training with long-term follow-up in a cohort of Rwandan physicians. Trop Med Int Health 21: 1531-1538.

81. Henwood PC, Mackenzie DC, Liteplo AS, Rempell JS, Murray AF, Leo MM, Dukundane D, Dean AJ, Rulisa S, Noble VE, 2017. Point-of-care ultrasound use, accuracy, and impact on clinical decision making in Rwanda hospitals. J Ultrasound Med 36: 1189-1194.

82. Terry B, Polan DL, Nambaziira R, Mugisha J, Bisanzo M, Gaspari $R, 2019$. Rapid, remote education for point-of-care ultrasound among non-physician emergency care providers in a resource limited setting. Afr J Emerg Med 9: 140-144.

83. Miller MA, Safadi S, Siegel A, Levine A, McCurdy M, 2019. Teleultrasound in resource-limited settings: a systematic review. Front Public Health 7: 244.

84. Cook NR, 2008. Statistical evaluation of prognostic versus diagnostic models: beyond the ROC curve. Clin Chem 54: 17-23.

85. Wynants L, Van Calster B, Collins GS, Riley RD, Heinze G, Schuit E, Bonten MM, Dahly DL, Damen JA, Debray TP, 2020. Prediction models for diagnosis and prognosis of COVID-19: systematic review and critical appraisal. Bmj 369: m1328.

86. Meng Z, Wang M, Song H, Guo S, Zhou Y, Li W, Zhou Y, Li M, Song X, Zhou Y, 2020. Development and utilization of an intelligent application for aiding COVID-19 diagnosis. medRxiv [Preprint]. doi: 10.1101/2020.03.18.20035816.

87. Feng $\mathrm{C}$, Huang Z, Wang L, Chen X, Zhai Y, Zhu F, Chen H, Wang $Y$, Su X, Huang S, 2020. A novel triage tool of artificial intelligence assisted diagnosis aid system for suspected COVID-19 pneumonia in fever clinics. medRxiv [Preprint]. doi: 10.2139/ssrn.3551355.

88. Song CY, Xu J, He JQ, Lu YQ, 2020. COVID-19 early warning score: a multi-parameter screening tool to identify highly suspected patients. medRxiv [Preprint]. doi: 10.1101/2020.03.05. 20031906

89. Caramelo F, Ferreira N, Oliveiros B, 2020. Estimation of risk factors for COVID-19 mortality-preliminary results. medRxiv [Preprint]. doi: 10.1101/2020.02.24.20027268.

90. Gong $\mathrm{J}$ et al., 2020. A tool to early predict severe 2019-novel coronavirus pneumonia (COVID-19): a multicenter study using 
the risk nomogram in Wuhan and Guangdong, China. Clin Infect Dis 71: 833-840.

91. Lu J et al., 2020. ACP risk grade: a simple mortality index for patients with confirmed or suspected severe acute respiratory syndrome coronavirus 2 disease (COVID-19) during the early stage of outbreak in Wuhan, China. medRxiv [Preprint]. doi: 10.1101/2020.02.20.20025510.

92. Shi $Y, Y u X$, Zhao H, Wang H, Zhao R, Sheng J, 2020. Host susceptibility to severe COVID-19 and establishment of a host risk score: findings of 487 cases outside Wuhan. Crit Care 24: 108.

93. Xie J et al., 2020. Development and external validation of a prognostic multivariable model on admission for hospitalized patients with COVID-19. medRxiv [Preprint]. doi: 10.1101/2020.03.28.20045997.

94. Yan L et al., 2020. Prediction of criticality in patients with severe COVID-19 infection using three clinical features: a machine learning-based prognostic model with clinical data in Wuhan. . medRxiv [Preprint]. doi: 10.1101/2020.02.27.20028027.

95. Haimovich AD, Ravindra NG, Stoytchev S, Young HP, Wilson FP, van Dijk D, Schulz WL, Taylor RA, 2020. Development and validation of the quick COVID-19 severity index: a prognostic tool for early clinical decompensation. Ann Emerg Med 76: 442-453.

96. Garcia PDW, Fumeaux T, Guerci P, Heuberger DM, Montomoli J, Roche-Campo F, Schuepbach RA, Hilty MP, Investigators $\mathrm{RI}, 2020$. Prognostic factors associated with mortality risk and disease progression in 639 critically ill patients with COVID-19 in Europe: initial report of the international RISC19-ICU prospective observational cohort. EClinicalMedicine 25: 100449

97. Yan L et al., 2020. An interpretable mortality prediction model for COVID-19 patients. Nat Mach Intell 14: 1-6.

98. Zhao Z, Chen A, Hou W, Graham JM, Li H, Richman PS, Thode HC, Singer AJ, Duong TQ, 2020. Prediction model and risk scores of ICU admission and mortality in COVID-19. PLoS One 15: e0236618.

99. Wu S, Du Z, Shen S, Zhang B, Yang H, Li X, Cui W, Chen F, Huang $J, 2020$. Identification and validation of a novel clinical signature to predict the prognosis in confirmed COVID-19 patients. Clin Infect Dis (Epub ahead of print, 2020 Jun 18): ciaa793. doi: 10.1093/cid/ciaa793.

100. Maguire D, Woods M, Richards C, Dolan R, Veitch JW, Sim WM, Kemmett OE, Milton DC, Randall SL, Bui LD, 2020. Prognostic factors in patients admitted to an urban teaching hospital with COVID-19 infection. J Trans/ Med 18: 1-10.

101. Grifoni E, Valoriani A, Cei F, Vannucchi V, Moroni F, Pelagatti L, Tarquini R, Landini G, Masotti L, 2020. The CALL score for predicting outcomes in patients with COVID-19.Clin Infect Dis 71: 1393-1399.

\section{APPENDIX}

Development of recommendations and suggestions. Selection of Task Force members. The selection of the group members was based on interest in specific aspects of coronavirus disease (COVID-19) and direct experience in low- and middle-income countries (LMICs). Alfred Papali and Marcus Schultz contacted potential team members through email and in person early in the COVID-19 pandemic and created 10 subgroups assigned to separate areas in COVID19 management: "triage," "safety," "organization," "diagnostics," "acute respiratory failure," "acute kidney injury," "coagulopathy," "therapeutics," "shock," and "support after initial care." In total, there were 38 Task Force members representing five medical specialties or disciplines (emergency medicine, intensive care, infectious diseases, internal medicine, and critical care nursing) from five out of six WHO geographic regions. The Task Force consisted of 16 full-time LMIC members, 16 full-time HIC members-all with direct LMIC experience, and six members with joint LMIC/HIC appointments.

Selection of subgroup members. Marcus Schultz, Tewodros Gebremariam, Casey Park, Luigi Pisani, Chaisith
Sivakorn, Shaurya Taran, and Alfred Papali were assigned to this subgroup based on their specific expertise and interest in microbiology and laboratory tests, imaging tools, and diagnostic and prognostic modeling.

Meetings. An initial Internet subgroup head meeting was held to establish the procedures for literature review and drafting of tables for evidence analysis. The subgroup heads continued work via the Internet. Several meetings occurred through electronic-based discussions among the subgroup heads and with members of other subgroups.

In the first meetings, a set of clearly defined questions regarding laboratory tests, imaging tools, and diagnostic and prognostic modeling were formulated. These questions were reviewed for content and clarity by the subgroup members and, subsequently, by the entire Task Force. After approval by the entire Task Force, the subgroup members split up, each seeking evidence for recommendations regarding the specific questions posed. During this process, the subgroup developed four major questions and formulated a set of recommendations and suggestions after online discussions. These were communicated among the subgroup members. After their approval, the subgroup sent an initial draft for review by the entire Task Force (first round), then, after revision, to the other subgroup heads (second round), then, after further revision, to the entire Task Force once again for final approval.

Search techniques. The literature search followed the same techniques as previously described. ${ }^{1}$ In case a question was identical to one in those recommendations, the subgroup members only searched for additional articles, specifically new investigations or meta-analyses related to the questions, in a minimum of one general database (i.e., MEDLINE and Embase) and the Cochrane Library. Furthermore, the subgroup members identified investigations from LMICs and also searched for unpublished study results.

Grading of Recommendations. The subgroup members classified quality of evidence as high, moderate, low, or very low recommendations as strong or weak. The factors influencing this classification are presented in Table A1.

The subgroup members paid extensive attention to several other factors as used before, but now focusing on LMICs, that is, availability, feasibility, and safety in LMICs. A strong recommendation was worded as "we recommend" and a weak recommendation as "we suggest." A number of recommendations could remain "ungraded" when, in the opinion of the subgroup members, such recommendations

TABLE A1

Quality of evidence

\begin{tabular}{lll}
\hline A & Randomized clinical trials & High \\
B & $\begin{array}{l}\text { Downgraded randomized clinical trial(s) or } \\
\text { upgraded observational studies }\end{array}$ & Moderate \\
C & $\begin{array}{l}\text { Observational studies } \\
\text { Downgraded observational studies or } \\
\text { D }\end{array}$ & Low \\
& Very low \\
\hline
\end{tabular}
Factors that may decrease strength of evidence include high likelihood of bias: inconsistency of results, including problems with subgroup analyses; indirectness of evidence (other population, intervention, control, outcomes, and comparison); imprecision of findings; and likelihood of reporting bias.

Factors that may increase strength of evidence: large magnitude of effect (direct evidence, relative risk $>2$ with no plausible confounders); very large magnitude of effect with relative risk $>5$ and no threats to validity (by two levels); and dose-response gradient.

Adapted from Dondorp AM, Dünser MW, Schultz MJ, eds., 2019. Sepsis Management in Resource-limited Settings. Springer. doi.org/10.1007/978-3-030-03143-5. 
TABLE A2

Strong vs. weak recommendations *

\begin{tabular}{|c|c|}
\hline What is considered & How it affects the recommendation \\
\hline High evidence & The higher the quality of evidence, the more likely a strong recommendation \\
\hline $\begin{array}{l}\text { Certainty about the balance of benefits vs. } \\
\text { harms and burdens }\end{array}$ & $\begin{array}{l}\text { The larger/smaller the difference between the desirable and undesirable consequences and the } \\
\text { certainty around that difference, the more likely a strong/weak recommendation }\end{array}$ \\
\hline Certainty in or similar values & The more certainty or similarity in values and preferences, the more likely a strong recommendation \\
\hline Resource implications & $\begin{array}{l}\text { The lower/higher the cost of an intervention compared to the alternative the more likely a strong/weak } \\
\text { recommendation }\end{array}$ \\
\hline Availability and feasibility in LMICs & The less available, the more likely a weak recommendation \\
\hline Affordability for LMICs & The less affordable, the more likely a weak recommendation \\
\hline Safety of the intervention in LMICs & The less safe in an LMIC, the more likely a weak recommendation \\
\hline
\end{tabular}

were not conducive for the process described earlier (Table A2).

Reporting. The report was edited for style and form by Alfred Papali and Marcus Schultz, with final approval by the entire "COVID-LMIC Task Force." A final document was submitted to the "American Journal of Tropical Medicine and Hygiene" for potential publication and made open access.
Conflicts of interest. No members of the "diagnostics" subgroup represented industry, and there was no industry input into guidelines development. No member of the "diagnostics" subgroup received honoraria for any role in the guideline development process. None reported conflicts of interest. Open access fees for this manuscript, and all nine others in the series, were supported by the Wellcome Trust of Great Britain. 